\title{
Diacylglycerol regulates acute hypoxic pulmonary vasoconstriction via TRPC6
}

\author{
Beate Fuchs ${ }^{1}$, Markus Rupp ${ }^{1}$, Hossein A Ghofrani ${ }^{1}$, Ralph T Schermuly ${ }^{1,2}$, Werner Seeger ${ }^{1,2}$, Friedrich Grimminger ${ }^{3}$, \\ Thomas Gudermann ${ }^{4}$, Alexander Dietrich ${ }^{4}$, Norbert Weissmann ${ }^{*}$
}

\begin{abstract}
Background: Hypoxic pulmonary vasoconstriction (HPV) is an essential mechanism of the lung that matches blood perfusion to alveolar ventilation to optimize gas exchange. Recently we have demonstrated that acute but not sustained HPV is critically dependent on the classical transient receptor potential 6 (TRPC6) channel. However, the mechanism of TRPC6 activation during acute HPV remains elusive. We hypothesize that a diacylglycerol (DAG)dependent activation of TRPC6 regulates acute HPV.
\end{abstract}

Methods: We investigated the effect of the DAG analog 1-oleoyl-2-acetyl-sn-glycerol (OAG) on normoxic vascular tone in isolated perfused and ventilated mouse lungs from TRPC6-deficient and wild-type mice. Moreover, the effects of OAG, the DAG kinase inhibitor R59949 and the phospholipase C inhibitor U73122 on the strength of HPV were investigated compared to those on non-hypoxia-induced vasoconstriction elicited by the thromboxane mimeticum U46619.

Results: OAG increased normoxic vascular tone in lungs from wild-type mice, but not in lungs from TRPC6deficient mice. Under conditions of repetitive hypoxic ventilation, OAG as well as R59949 dose-dependently attenuated the strength of acute HPV whereas U46619-induced vasoconstrictions were not reduced. Like OAG, R59949 mimicked HPV, since it induced a dose-dependent vasoconstriction during normoxic ventilation. In contrast, U73122, a blocker of DAG synthesis, inhibited acute HPV whereas U73343, the inactive form of U73122, had no effect on HPV.

Conclusion: These findings support the conclusion that the TRPC6-dependency of acute HPV is induced via DAG.

\section{Introduction}

Hypoxic pulmonary vasoconstriction (HPV) is an essential mechanism in the lung matching blood perfusion to alveolar ventilation, thus optimising gas exchange [1]. Despite decades of research, the signaling pathway underlying HPV has still not been fully resolved. An increase in intracellular calcium concentration $\left(\left[\mathrm{Ca}^{2+}\right]_{\mathrm{i}}\right)$ is an essential component in this process, leading to the contraction of precapillary pulmonary arteries [2-4]. However, how $\left[\mathrm{Ca}^{2+}\right]_{\mathrm{i}}$ is regulated in HPV is still a matter of debate $[2,3,5,6]$. In addition to L-type voltageoperated calcium channels (VOCC), non-selective transient receptor potential (TRP) channels have been

\footnotetext{
* Correspondence: norbert.weissmann@innere.med.uni-giessen.de ${ }^{1}$ Excellence Cluster Cardio-Pulmonary System, University of Giessen Lung Center, Dept. of Internal Medicine II, Justus-Liebig-University Giessen, Giessen, Germany

Full list of author information is available at the end of the article
}

suggested as important regulators of vascular tone in hypoxia [7-9]. In mammals, the family of TRP channels comprises 6 subfamilies, based on their sequence homology [10]. Among these, classical TRPC proteins are expressed in pulmonary arterial smooth muscle $[4,5,9]$, specifically, in smooth muscle cells of distal pulmonary arteries [11], which are suggested to be $\mathrm{O}_{2}$ sensor and effector cells of acute HPV [12]. Focusing on these aspects, the transient receptor potential channel (TRPC) 6 has recently been identified to be essential for acute but not sustained HPV in mice [9]. In this regard it is important to mention that HPV has repeatedly been shown to consist of two phases. An acute phase occurring within several minutes and a sustained phase developing within more than 30 min of hypoxic ventilation [12-17]. TRPC6 belongs to the TRPC3/6/7 subfamily of TRP channels which can be activated by diacylglycerol (DAG) [18], independently of protein 
kinase C $[19,20]$. Hypoxia induces an accumulation of DAG in isolated pulmonary artery smooth muscle cells (PASMC) [9].

We therefore hypothesize that DAG contributes also to the regulation of acute HPV and that the DAG signaling pathway involves TRPC6 in intact lungs.

DAG synthesis results from activation of G-protein coupled receptors or receptor tyrosine kinases and subsequent activation of phospholipase $\mathrm{C}$ isoforms (PLC $\beta$ or PLC $\gamma$ ) leading to hydrolysis of phosphatidylinositol 4,5bisphosphate $\left(\mathrm{PIP}_{2}\right)$ [21]. The degradation of DAG is catalyzed by DAG kinases to phosphatidic acid (PA) [22].

\section{Materials and methods \\ Animals}

All animal experiments were approved by the local authorities. Adult C57/BL6 mice were obtained from Charles River Laboratories (Sulzfeld, Germany). TRPC6 deficient (TRPC6 ${ }^{-/-}$) mice were generated as described previously [7]. Respective wild-type (WT) littermates from this colony were used as controls.

\section{Isolated lung perfusion and ventilation}

The model of isolated, perfused mouse lungs has been described previously [23]. Briefly, lungs were excised under deep anesthesia, perfused with Krebs-Henseleit buffer ( $\mathrm{pH} 7.37-7.40$ ) in a recirculating system, and ventilated with a mixture of $21 \% \mathrm{O}_{2}, 5.3 \% \mathrm{CO}_{2}$ and the balance $\mathrm{N}_{2}$ (normoxic ventilation). The pressure in the pulmonary artery and in the left atrium was measured by small diameter catheters.

\section{Induction of acute vasoconstriction}

Repetitive hypoxic maneuvers of 10-minute duration interrupted by 15 -min periods of normoxia were performed. The effects of the various pharmacological agents on pressure responses provoked by alveolar hypoxia $\left(1 \% \mathrm{O}_{2}, 5.3 \% \mathrm{CO}_{2}\right.$ and the balance $\left.\mathrm{N}_{2}\right)$ were determined within such a sequence of repetitive hypoxic maneuvers. $1 \% \mathrm{O}_{2}$ was chosen for hypoxic ventilation as this degree of hypoxia resulted in the most prominent HPV as described before also for other species [24]. Normoxic pulmonary arterial pressure was quantified directly before each hypoxic ventilation maneuver.

To evaluate the specific role of the agents applied in HPV intrinsic pathways, the effect on hypoxia-independent vasoconstriction was determined, using the thromboxane mimetic U46619 [25]. In these experiments, the ventilation remained normoxic, and the lungs were challenged with $4.5 \mathrm{nM}$ U46619 (Paesel and Lorei, Duisburg, Germany; $5.7 \mathrm{mM}$ stock solution in DMSO), applied as a bolus into the pulmonary arterial line. Such bolus applications were repeated every $25 \mathrm{~min}$.
The experiments with $\mathrm{TRPC6}^{-/-}$mice as well as their WT controls were performed during continuous normoxic ventilation.

\section{Application of the agents}

After the second hypoxic maneuver, the DAG analog 1-oleoyl-2-acetyl-sn-glycerol (OAG), the DAG kinase inhibitor R59949, the PLC inhibitor U73122 or its inactive form (U73343) were applied into the recirculating perfusion medium $10 \mathrm{~min}$ prior to the next hypoxic or U46619 challenge with a stepwise increasing dose. For application stock solutions of OAG (50 mM; SigmaAldrich, Steinheim, Germany) and R59949 (100 mM; Calbiochem, Bad Soden, Germany) were prepared in DMSO (Merck, Darmstadt, Germany). U73122 and U73343 were dissolved in 96\% Ethanol (Fischer, Saarbrücken, Germany) with a stock concentration of $1 \mathrm{mM}$.

Control experiments were performed with the application of the respective solvents alone.

\section{The effect of the DAG kinase inhibitor R59949 on sustained HPV}

To investigate the effect of the DAG kinase inhibitor R59949 on sustained HPV lungs were ventilated for 120 min with a hypoxic gas mixture $\left(1 \% \mathrm{O}_{2}, 5.3 \% \mathrm{CO}_{2}\right.$ and the balance $\mathrm{N}_{2}$ ) and $\mathrm{R} 59949$ was added to the perfusate $10 \mathrm{~min}$ prior to the onset of hypoxia. R59949 was applied in a concentration $(10 \mu \mathrm{M})$ that inhibited acute HPV by approximately $50 \%$. To characterize a possible sustained effect of R59949 on normoxic vascular tone this agent was applied in an analog schedule but during normoxic ventilation. Control experiments were carried out with the application of the solvent only.

\section{Analysis}

The strength of acute HPV is given as the maximum increase in pulmonary arterial pressure $(\triangle \mathrm{PAP})$, referenced to the second hypoxic challenge (set at $100 \%$ ). Changes of the normoxic pulmonary arterial pressure $(\triangle \mathrm{PAP})$ in these experiments were referenced to the normoxic PAP directly before the second hypoxic maneuver. The U46619 and normoxic experiments are displayed accordingly. For sustained HPV the increase in pulmonary arterial pressure is given. All values are expressed as means \pm SEM (standard error of the mean). Statistical analysis was performed using ANOVA with the Student-Newman-Keuls post hoc test or Student's $t$-test with Welsh's correction as appropriate. A p-value $<0.05$ was considered significant.

\section{Results}

OAG-induced activation of TRPC6 under normoxic conditions To decipher a possible role for DAG in TRPC6 activation, the effect of the membrane-permeable analog of 
DAG, OAG, on pulmonary artery pressure was investigated in TRPC6 ${ }^{-/-}$and WT mice. As illustrated in Figure 1, OAG increased PAP dose-dependently only in WT mice but not in TRPC6 $^{-1-}$ mice. PAP measured after the initial steady state period was $9.9 \pm 0.1 \mathrm{mmHg}(\mathrm{n}=9)$ and was not different between WT and TRPC6 ${ }^{-1-}$ mice.

To address the role played by DAG in acute HPV, the effect of the DAG analog OAG as well as of inhibitors of both PLC and DAG kinase on HPV and normoxic vascular tone was assessed.

\section{The effect of OAG on acute hypoxia-induced vasoconstriction}

In experiments with repetitive hypoxic ventilation maneuvers, normoxic PAP, assessed prior to each repetitive hypoxic challenge, was dose-dependently increased by OAG (Figure 2A). In parallel with this increase, the strength of HPV was diminished (Figure 2B). This effect was specific for HPV, since vasoconstriction induced by the thromboxane mimetic U46619 was not suppressed, but was rather increased by OAG (Figure 2C).

PAP measured after the initial steady state period, prior to the first vasoconstrictor provocation was $9.9 \pm$ $0.1 \mathrm{mmHg}(\mathrm{n}=20)$, and was not different between experiments with OAG application and solvent alone. Absolute $\triangle$ PAP values for the strength of HPV and U46619-induced vasoconstrictions were calculated at $1.6 \pm 0.2 \mathrm{mmHg}(\mathrm{n}=10)$ and $2.0 \pm 0.2 \mathrm{mmHg}(\mathrm{n}=10)$.

\section{The effect of the DAG kinase inhibitor R59949 on acute} hypoxia-induced vasoconstriction

As DAG is degraded by DAG kinases [22,26], the effect of the DAG kinase inhibitor R59949 on normoxic PAP,

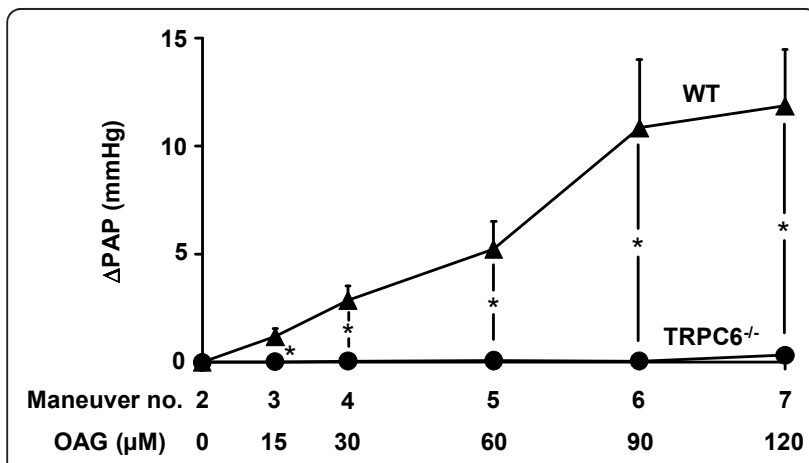

Figure 1 No effect of 1-oleoyl-2-acetyl-sn-glycerol (OAG) on normoxic vascular tone in TRPC6 ${ }^{-/-}$mouse lungs. The effect of OAG was investigated in isolated wild-type and TRPC $6^{-/-}$mouse lungs. The OAG-induced vasoconstriction is represented as the increase in pulmonary artery pressure $(\triangle P A P)$ during normoxic ventilation. OAG was applied in increasing doses every 25 min. Data are derived from $n=5$ and $n=4$ wild-type and TRPC $6^{-/}$mice, respectively. * Significant differences compared to wild-type mice $(p<0.05)$ the strength of HPV, as well as U46619-induced vasoconstrictions was investigated. As seen for OAG, the DAG kinase inhibitor dose-dependently increased normoxic PAP (Figure 3A). In parallel, the strength of HPV was reduced by R59949 and was completely abolished at $25 \mu \mathrm{M}$ (Figure 3B). The inhibitory effect was specific for HPV, since R59949 caused no significant inhibition of U46619-induced vasoconstrictions, but amplification at higher concentrations (Figure 3C).

The effect of the PLC inhibitor U73122 on acute hypoxiainduced vasoconstriction

As PLC catalyzes the production of DAG [27], the impact of PLC on HPV was investigated by application of the PLC inhibitor U73122. As expected, U73122 did not significantly alter normoxic PAP. The same was true for control experiments with the inactive form of the PLC inhibitor (U73343) or the solvent of the PLC inhibitor (Figure 4A). In contrast, U73122 dose-dependently inhibited the strength of HPV (Figure 4B). However, U46619-induced vasoconstrictions were also diminished (Figure 4C). These effects were absent in experiments with the inactive compound, or the solvent of the PLC inhibitor applied alone.

\section{The effect of the DAG kinase inhibitor R59949 on sustained HPV}

A single application of $10 \mu \mathrm{M}$ R59949, a concentration that inhibited acute HPV by approximately $50 \%$, resulted in a transient vasoconstriction under normoxic ventilation. The maximum increase in PAP occurred after $18 \pm$ 2 min (Figure 5a). Although this dosage still inhibited acute HPV when hypoxic ventilation was performed 120 min after a single application of R59949 (data not given), no sustained elevation of PAP was noted during continuous normoxic ventilation: significant differences in PAP in comparison to the solvent control could be detected for time points $\leq 70 \mathrm{~min}$ only (Figure $5 \mathrm{a}$ ). If R59949 was applied prior to a 120 min period of hypoxic ventilation, only the acute but not the sustained phase of HPV was inhibited (Figure 5b).

\section{Discussion}

The major finding of this study is that the initiation of acute HPV occurs via a DAG-mediated activation of TRPC6 in mice.

Regarding the vascular effects of alveolar hypoxia, it has previously been shown that these can be divided into three phases, one occurring within seconds, a second developing upon hypoxic ventilation of more than $20 \mathrm{~min}$, and a third which includes a vascular remodeling process, permanently decreasing the area of the vascular lumen [12]. Although some heterogeneity as to the kinetics of the first two phases has been described 
A

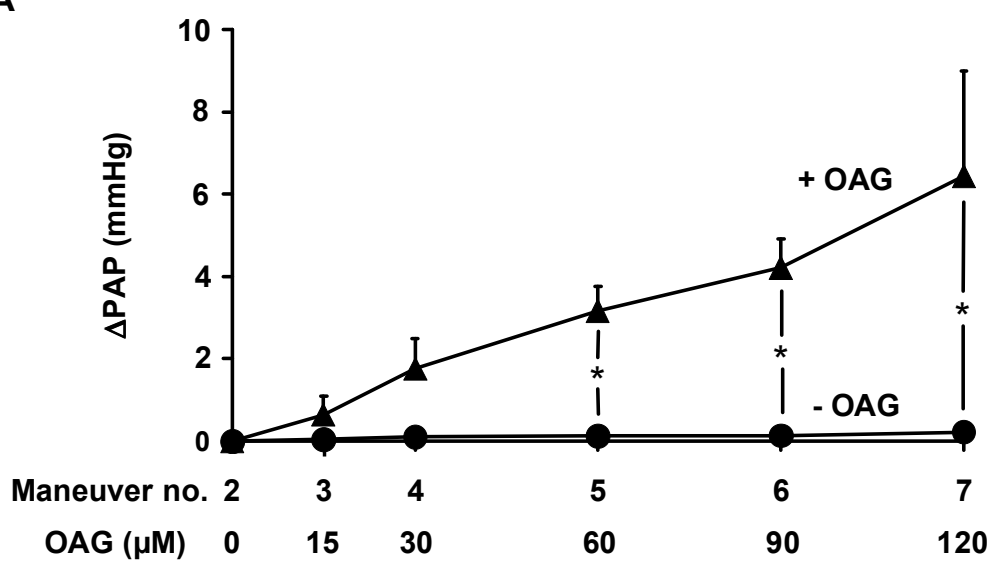

B

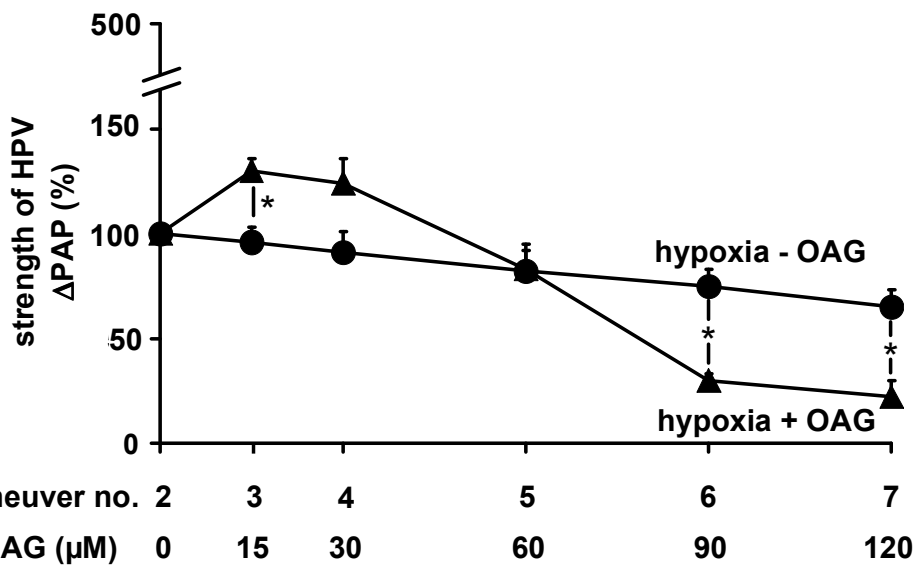

C

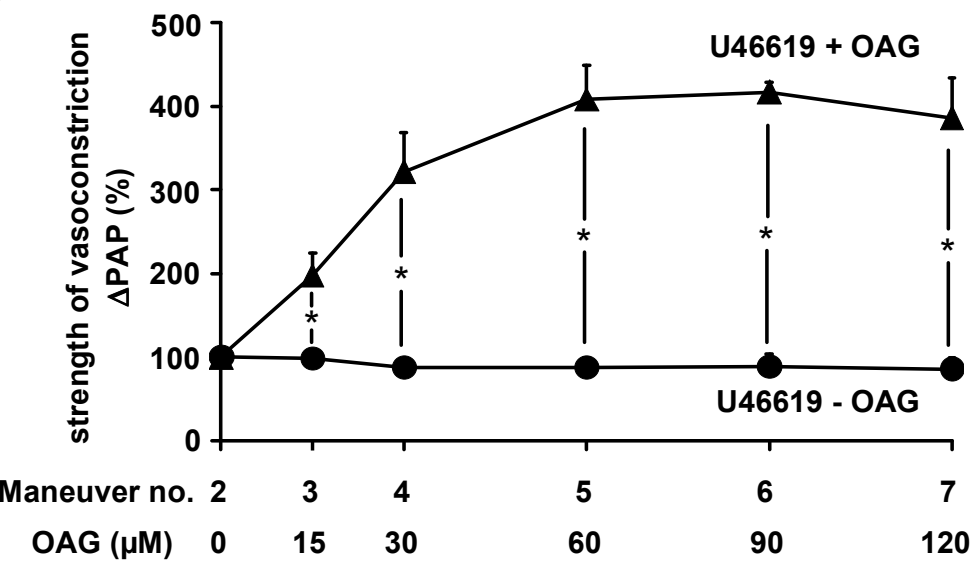

Figure 2 1-oleoyl-2-acetyl-sn-glycerol (OAG) diminished HPV specifically. The effect of OAG as well as its solvent on the normoxic vascular tone, the strength of HPV, and the strength of U46619-induced vasoconstriction was investigated in isolated wild-type mouse lungs. (A) Increase in normoxic pulmonary arterial pressure $(\triangle P A P)$, assessed directly before each hypoxic ventilation maneuver. (B) Strength of HPV referenced to the effect of the second hypoxic ventilation maneuver $(=100 \%)$. (C) Strength of the U46619-induced vasconstriction, referenced to the effect of the second U46619 application ( $=100 \%$ ). Data are derived from $n=5$ isolated lung preparations each. * Significant differences compared to control experiments with application of the solvent only $(p<0.05)$. 
A

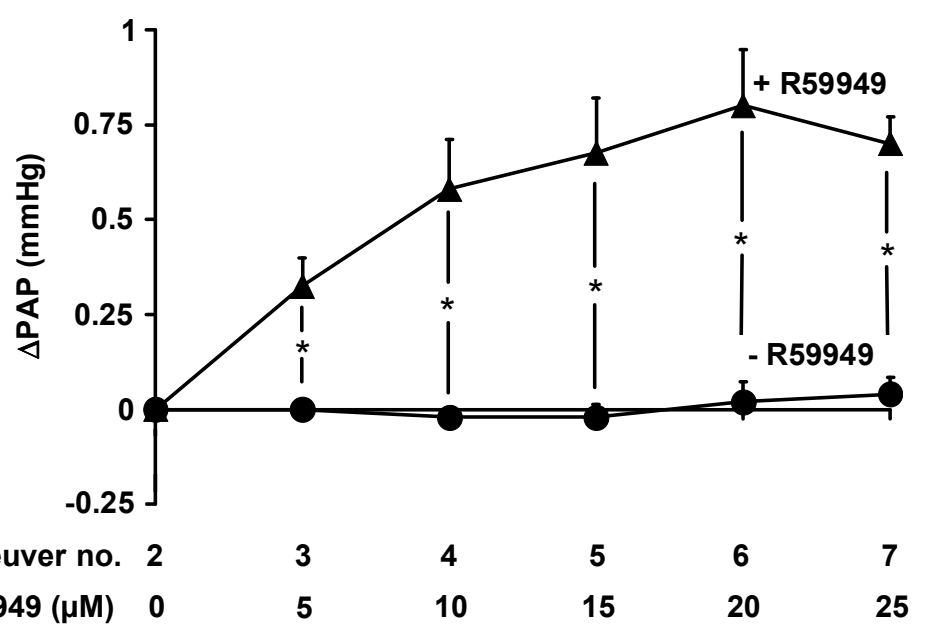

B

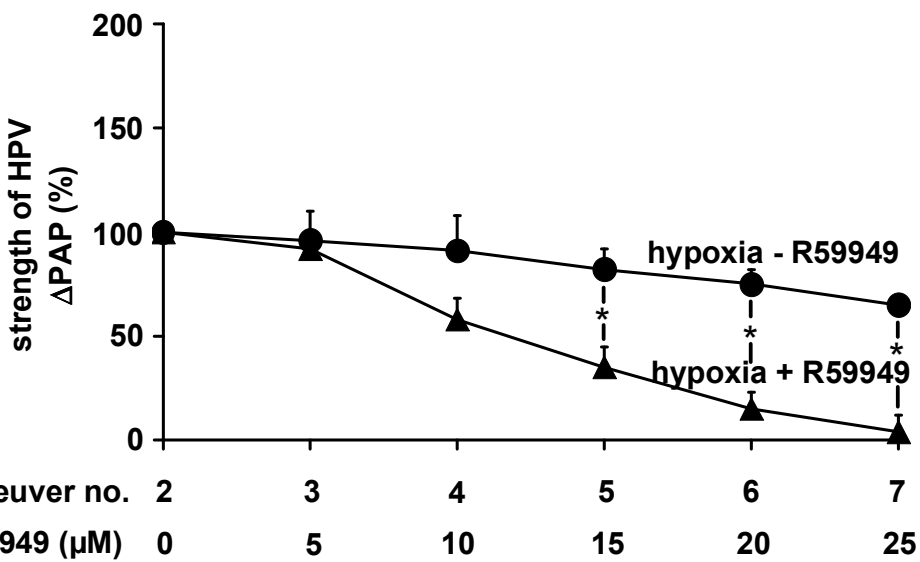

C

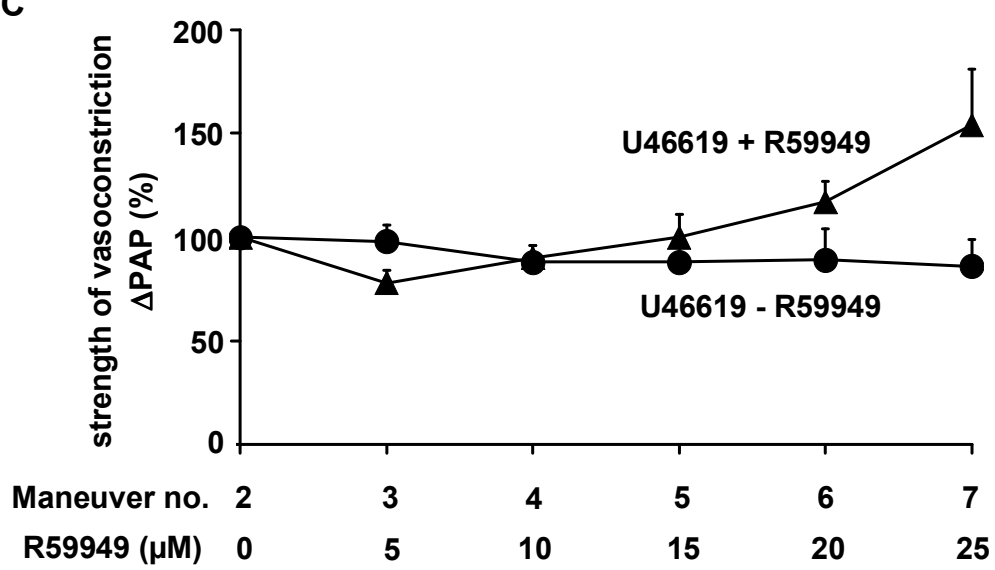

Figure 3 Diacylglycerol kinase inhibitor R59949 diminished HPV specifically. The effect of the diacylglycerol kinase inhibitor R59949 as well as its solvent on the normoxic vascular tone, the strength of HPV, and the strength of U46619-induced vasoconstriction was investigated in isolated wild-type mouse lungs. (A) Increase in normoxic pulmonary arterial pressure ( $\triangle P A P)$, assessed directly before each hypoxic ventilation maneuver. (B) Strength of HPV referenced to the effect of the second hypoxic ventilation maneuver $(=100 \%)$. Absolute values of HPV for the second hypoxia maneuver prior to R59949 application were $0.7 \pm 0.1(n=5)$. (C) Strength of the U46619-induced vasoconstriction, referenced to the effect of the second U46619 application (= 100\%). Data are derived from $n=5$ isolated lung preparations each. * Significant differences compared to control experiments with application of the solvent only $(p<0.05)$. 


\section{A}

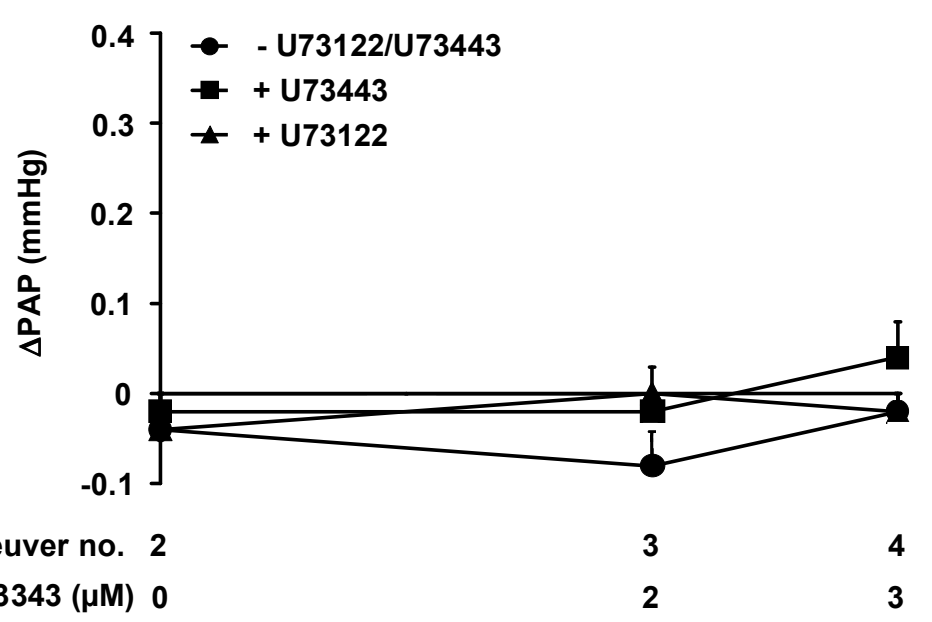

B

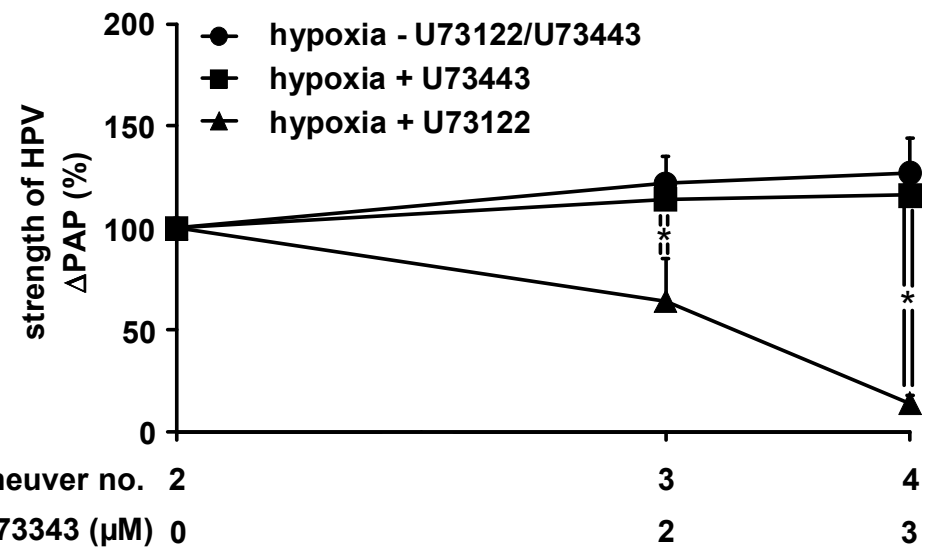

C

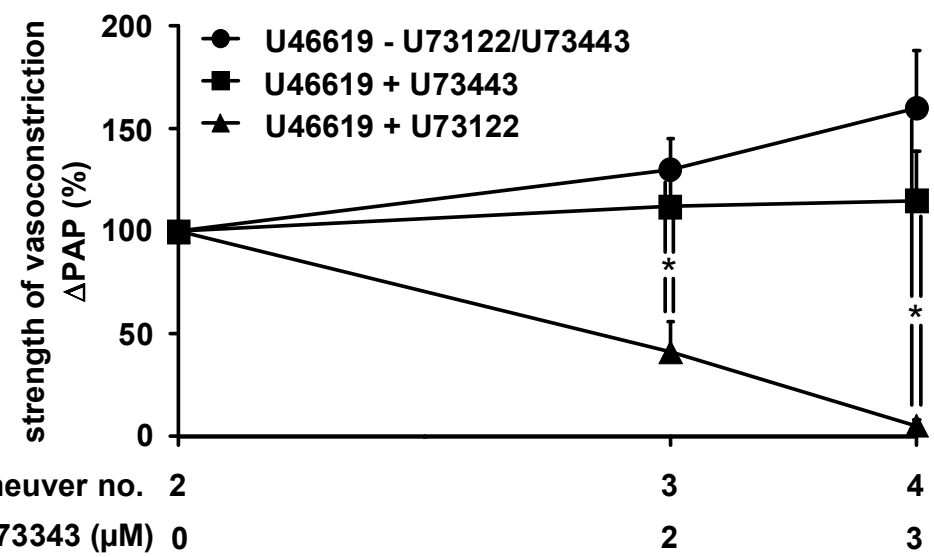

Figure 4 Inhibitory effect of phospholipase C inhibitor U73122 on HPV and U46619-induced vasoconstriction. The effect of the active (U73122) and inactive (U73343) form of phospholipase C inhibitor as well as their solvent on the normoxic vascular tone, the strength of HPV, and the strength of U46619-induced vasoconstriction was investigated in isolated wild-type mouse lungs. (A) Increase in normoxic pulmonary arterial pressure ( $\triangle P A P)$, assessed directly before each hypoxic ventilation maneuver. (B) Strength of HPV referenced to the effect of the second hypoxic ventilation maneuver (= 100\%). (C) Strength of U46619-induced vasoconstrictions, referenced to the effect of the second U46619 application $(=100 \%)$. Data are derived from $n=5$ isolated lung preparations each. ${ }^{*}$ Significant differences compared to control experiments with application of the solvent only $(p<0.05)$. 

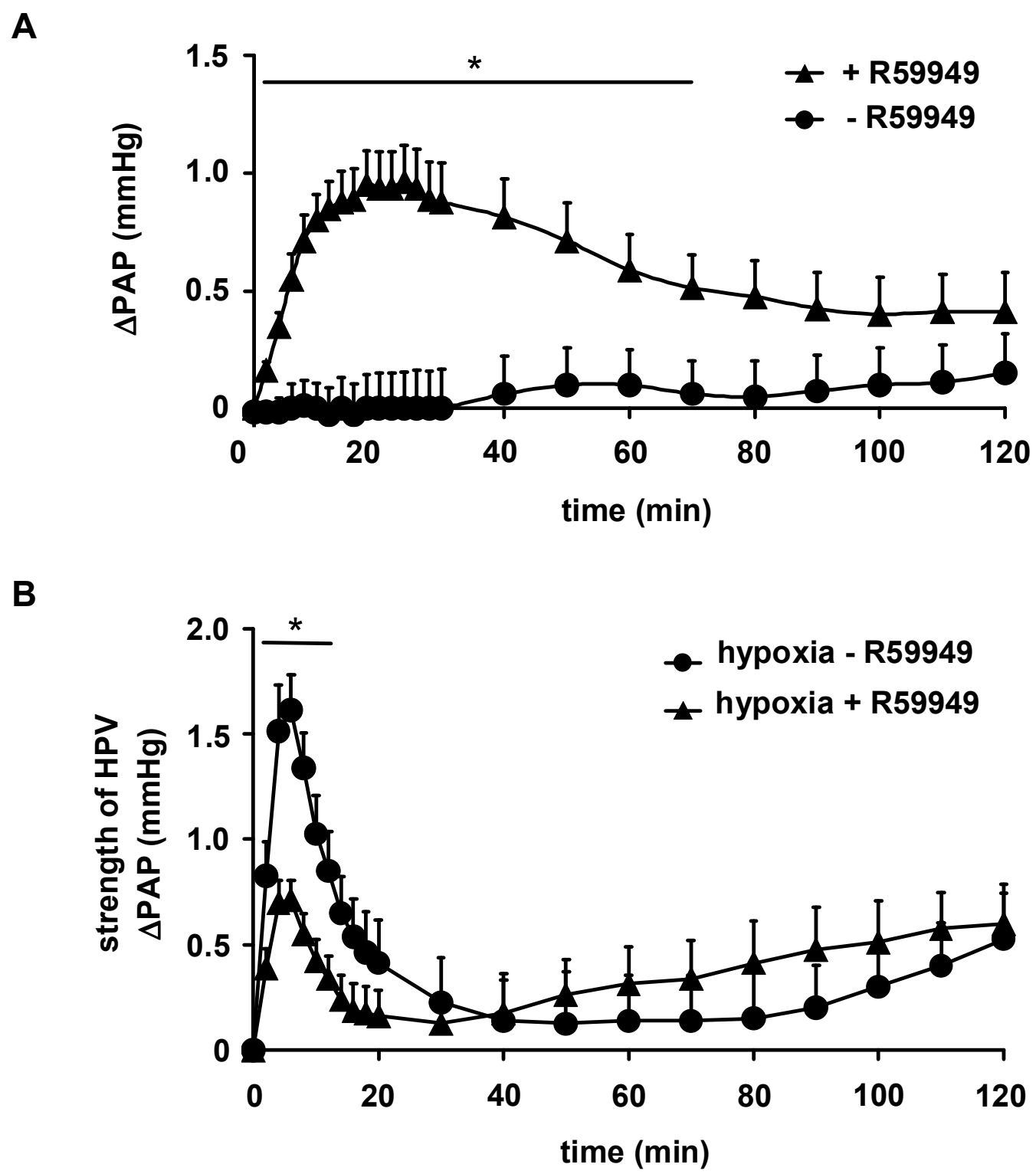

Figure 5 Inhibition of acute but not sustained HPV by the diacylglycerol kinase inhibitor R59949. The effect of the diacylglycerol kinase inhibitor R59949 as well as its solvent on normoxic vascular tone and sustained HPV was investigated for a period of 120 min. (A) Increase in normoxic pulmonary arterial pressure ( $\triangle \mathrm{PAP}$ ) referenced to the value directly before R59949 application. For comparison changes in PAP are given for normoxic lungs in the absence of R59949. (B) Strength of sustained HPV in the presence and the absence of R59949. Data are derived from $n=8$ isolated lung preparations each. * Significant differences compared to experiments in the absence of R59949 $(p<0.05)$.

[26,28-31], it was recently demonstrated that TRPC6 is essential for the acute phase, but not the sustained or chronic vascular effects in mice [9]. However, it has not yet been clarified which pathway controls TRPC6 in acute HPV. TRPC6 is a member of the DAG-sensitive TRPC3/6/7 subfamily, which has been shown to increase $\left[\mathrm{Ca}^{2+}\right]_{\mathrm{i}}$ in a membrane-delimited fashion, independently of protein kinase C [32]. TRPC6 is insensitive to activation by inositol 1,4,5-trisphosphate at the cellular level [33]. As to the DAG-sensitive nature of TRPC6, it was hypothesized that an increase in DAG induces HPV via this channel. This hypothesis was derived from previous findings in isolated PASMC that 1) hypoxia causes an accumulation of DAG at the cell membrane and that 2) the DAG kinase inhibitor causes an increase in $\left[\mathrm{Ca}^{2+}\right]_{\mathrm{i}}$ in these cells. In this study, it is documented for the first time in intact lungs that the membranepermeable analog of DAG, OAG, induces a vasoconstriction in WT mice which is mediated via TRPC6. This can be concluded from the observation that the 
DAG-induced vasoconstriction was absent in $\mathrm{TRPC6}^{-/-}$ mice, although it has been previously demonstrated that TRPC $^{-1-}$ mice do not lack non-hypoxia-induced vasoconstrictor responses [9]. The latter finding excludes a general lack of vasocontractility in TRPC6-/- mice.

The central role of DAG in acute HPV was further supported by the effects of the DAG analog OAG, as well as the DAG kinase inhibitor and the phospholipase $\mathrm{C}$ inhibitor. Along these lines, it has been shown that DAG accumulation can be caused by inhibition of DAG kinases [34] but also by activation of PLC [35].

OAG did not only induce a vasoconstrictor response under normoxic conditions but also inhibited the subsequent acute HPV during hypoxia. Consistent with this idea, an increase in cellular DAG levels by the application of DAG kinase inhibitor [34] increased vasoconstriction, but decreased the subsequent acute HPV. Thus, both OAG and R59949 interfere with the same signal transduction cascade inducing acute HPV and therefore mimic this physiological response under normoxic conditions. The fact that low doses of OAG slightly increased the strength of HPV maybe is induced by the supplementary effect of the exogenous OAG in addition to the endogenous DAG produced by acute hypoxia. The inhibition of HPV caused by OAG or R59949 was specific for HPV as non-hypoxia-induced vasoconstriction induced by U46619 was not inhibited by either agent.

The notion that OAG-induced vasoconstrictions under normoxia were somewhat higher than the strength of HPV indicates, as expected, that DAG not only specifically mediates hypoxia-induced vasoconstrictions but also contributes to non-hypoxia-induced vasoconstrictions as previously shown for $\mathrm{G}$ protein coupled receptors [36].

In contrast to those agents which mimic acute HPV or increase DAG levels, the PLC inhibitor U73122 should decrease intracellular DAG production [37] and thus should suppress but not mimic HPV. As expected, while not mimicking acute HPV, U73122 suppressed HPV. It is unlikely that this effect is due to an unspecific inhibition of other signaling processes, because the inactive but structurally analogous - compound U73343 had no effect on acute HPV. The fact, that U46619-induced vasoconstrictions were also suppressed by the PLC but not the DAG kinase inhibitor, supports the notion that the thromboxane mimetic-induced vasoconstriction is dependent on PLC without triggering the DAG-TRPC6axis. In this regard it was shown that activation of thromboxane receptors can contribute to contraction of bovine pulmonary arteries by depletion of intracellular calcium stores and calcium entry via store-operated calcium channels [38]. Besides a role of store-operated calcium channels, U46619-induced contraction was also shown to be dependent at least in part on calcium entry through VOCC [35]. In this process, ROS-induced PKC zeta activation inhibited voltage-gated potassium (Kv) channel activity leading to membrane depolarization and activation of VOCC [36,37]. Moreover, PKC can generally also be activated by DAG [38]. Triggering different pathways, cell-compartmentalization, as well as some synergism of the above pathways may explain the increase of U46619-induced vasoconstrictions after application of the DAG analog OAG. Thus, the enhancement of U46619-induced vasoconstrictions, in contrast to the inhibition of HPV, further supports the specific role of DAG in acute HPV signaling. A compartmentalized effect of DAG regulation in HPV is further supported by the fact that the DAG kinase inhibitor R59449 did not amplify U46619-induced but selectively inhibited HPV.

The fact that the DAG kinase inhibitor R59449 inhibited only acute HPV but not sustained HPV and mimicked only acute but not sustained HPV during normoxic ventilation is well in line with our previous finding that DAG-regulated TRPC6 channels are essential for acute but not sustained HPV.

With regard to previous findings that acute HPV may be regulated by reactive oxygen species [39-43], we speculate that DAG levels activating TRPC6 can be increased by a redox-dependent mechanism. This can hypothetically be caused by a redox-dependent modulation of e.g. DAG kinase activity. In addition to TRPC6, it was shown that $\mathrm{Kv}$ channels are essential for acute HPV $[44,45]$. Although our current study did not investigate a possible effect of the DAG-TRPC6-axis on the closure of $\mathrm{Kv}$ channels in $\mathrm{HPV}$, these two systems may be linked via modulation of the cellular sodium concentration as previously suggested [46]. This concept would be in line with the lack of acute HPV recently described in malonyl-CoA decarboxylase deficient mice, which lack hypoxic mitochondrial ROS signaling and Kv channel inhibition [40].

The specific role of DAG in mediating acute HPV shown in our isolated lung experiments (where the endothelium is present) and in our previous study [9] in isolated PASMC (where the increase in $\left[\mathrm{Ca}^{2+}\right]_{\mathrm{i}}$ was used as a readout for HPV) indicates that the oxygen sensing process underlying HPV resides in the PASMC. This is well in line with numerous previous findings [47-50] and the notion expressed by others that acute HPV (in contrast to sustained) is independent from the endothelium $[13,15,17,51]$. This, however, does not exclude an important role of the endothelium in modulating HPV, though not contributing to oxygen sensing. This interpretation is well in line with the finding by us and others that isolated PASMC need to be "primed" by e.g. endothelin-1 as a prerequisite for functional oxygen 
sensing $[9,52-54]$ and allows the suggestion that a basic stimulation of DAG production by G-protein coupled receptors is a prerequisite for oxygen sensing and signal transduction of acute HPV, occurring cell compartmentspecific by DAG kinase inhibition.

\section{Conclusions}

To summarize, DAG was identified as an important mediator in the signaling pathway underlying acute HPV. Moreover, these data indicate that DAG activates TRPC6 as an essential step in the mechanism of acute HPV.

\section{Acknowledgements}

This work was supported by the Deutsche Forschungsgemeinschaft (DFG DI 514/8-1, DFG WE 1978/4-1), the Excellence Cluster Pulmonary System (ECCPS), and the von-Behring-Röntgen-Stiftung. The authors thank Dr. Rory Morty, Giessen, for linguistic editing of the manuscript.

\section{Author details}

${ }^{1}$ Excellence Cluster Cardio-Pulmonary System, University of Giessen Lung Center, Dept. of Internal Medicine II, Justus-Liebig-University Giessen, Giessen, Germany. ${ }^{2}$ Max-Planck-Institute for Heart and Lung Research, Bad Nauheim, Germany. ${ }^{3}$ Excellence Cluster Cardio-Pulmonary System, University of Giessen Lung Center, Dept. of Internal Medicine IVN, Justus-LiebigUniversity Giessen, Giessen, Germany. ${ }^{4}$ Walter-Straub-Institute for Pharmacology and Toxicology, Ludwig-Maximilians-University Munich, Munich, Germany.

\section{Authors' contributions}

BF participated in the design, analysis and interpretation of experiments, performed statistical analysis, and designed and drafted the manuscript together with NW and AD. MR performed most of the experiments and has made substantial contributions to analysis and interpretation and statistical analysis of the data. HAG, RTS, WS, and FG participated in the design of the experiments and in the interpretation of the results. TG and AD supplied and/or generated the TRPC $6^{-/-}$mice and developed the hypothesis together with NW and BF. Their contribution was critical for intellectual content and designed portions of the experiments. NW designed and supervised the study, interpreted the data and drafted the manuscript together with BF and AD. All authors read and approved the final manuscript.

\section{Competing interests}

The authors declare that they have no competing interests.

Received: 13 October 2010 Accepted: 4 February 2011

Published: 4 February 2011

\section{References}

1. Weissmann N, Sommer N, Schermuly RT, Ghofrani HA, Seeger W, Grimminger F: Oxygen sensors in hypoxic pulmonary vasoconstriction. Cardiovasc Res 2006, 71:620-629.

2. Weigand L, Foxson J, Wang J, Shimoda LA, Sylvester JT: Inhibition of hypoxic pulmonary vasoconstriction by antagonists of store-operated $\mathrm{Ca} 2+$ and nonselective cation channels. Am J Physiol Lung Cell Mol Physiol 2005, 289:L5-L13.

3. Wang J, Shimoda LA, Weigand L, Wang W, Sun D, Sylvester JT: Acute hypoxia increases intracellular $[\mathrm{Ca} 2+]$ in pulmonary arterial smooth muscle by enhancing capacitative Ca2+ entry. Am J Physiol Lung Cell Mol Physiol 2005, 288:L1059-L1069.

4. McDaniel SS, Platoshyn O, Wang J, Yu Y, Sweeney M, Krick S, Rubin LJ, Yuan JX: Capacitative $\mathrm{Ca}(2+)$ entry in agonist-induced pulmonary vasoconstriction. Am J Physiol Lung Cell Mol Physiol 2001, 280:L870-L880.

5. Ward JP, Robertson TP, Aaronson PI: Capacitative calcium entry: a central role in hypoxic pulmonary vasoconstriction? Am J Physiol Lung Cell Mol Physiol 2005, 289:L2-L4.
6. Aaronson PI, Robertson TP, Knock GA, Becker S, Lewis TH, Snetkov V, Ward JP: Hypoxic pulmonary vasoconstriction: mechanisms and controversies. J Physiol 2006, 570:53-58.

7. Dietrich A, Mederos YS, Gollasch M, Gross V, Storch U, Dubrovska G, Obst M, Yildirim E, Salanova B, Kalwa H, Essin K, Pinkenburg O, Luft FC, Gudermann T, Birnbaumer L: Increased vascular smooth muscle contractility in TRPC6-/- mice. Mol Cell Biol 2005, 25:6980-6989.

8. Owsianik G, Talavera K, Voets T, Nilius B: Permeation and selectivity of TRP channels. Annu Rev Physiol 2006, 68:685-717.

9. Weissmann N, Dietrich A, Fuchs B, Kalwa H, Ay M, Dumitrascu R, Olschewski A, Storch U, Schnitzler M, Ghofrani HA, Schermuly RT, Pinkenburg O, Seeger W, Grimminger F, Gudermann T: Classical transient receptor potential channel 6 (TRPC6) is essential for hypoxic pulmonary vasoconstriction and alveolar gas exchange. Proc Natl Acad Sci USA 2006, 103:19093-19098.

10. Dietrich A, Chubanov V, Kalwa H, Rost BR, Gudermann T: Cation channels of the transient receptor potential superfamily: their role in physiological and pathophysiological processes of smooth muscle cells. Pharmacol Ther 2006, 112:744-760.

11. Wang J, Shimoda LA, Sylvester JT: Capacitative calcium entry and TRPC channel proteins are expressed in rat distal pulmonary arterial smooth muscle. Am J Physiol Lung Cell Mol Physiol 2004, 286:L848-L858.

12. Weissmann N, Grimminger F, Olschewski A, Seeger W: Hypoxic pulmonary vasoconstriction: a multifactorial response? Am J Physiol Lung Cell Mol Physiol 2001, 281:L314-L317.

13. Ward JP, Aaronson PI: Mechanisms of hypoxic pulmonary vasoconstriction: can anyone be right? Respir Physiol 1999, 115:261-271.

14. Weissmann N, Zeller S, Schafer RU, Turowski C, Ay M, Quanz K, Ghofrani HA, Schermuly RT, Fink L, Seeger W, Grimminger F: Impact of mitochondria and NADPH oxidases on acute and sustained hypoxic pulmonary vasoconstriction. Am J Respir Cell Mol Biol 2006, 34:505-513.

15. Robertson TP, Aaronson PI, Ward JP: Ca2+ sensitization during sustained hypoxic pulmonary vasoconstriction is endothelium dependent. Am J Physiol Lung Cell Mol Physiol 2003, 284:L1121-L1126.

16. Dipp M, Nye PC, Evans AM: Hypoxic release of calcium from the sarcoplasmic reticulum of pulmonary artery smooth muscle. Am J Physiol Lung Cell Mol Physiol 2001, 281:L318-L325.

17. Aaronson PI, Robertson TP, Ward JP: Endothelium-derived mediators and hypoxic pulmonary vasoconstriction. Respir Physiol Neurobiol 2002, 132:107-120.

18. Dietrich A, Kalwa H, Rost BR, Gudermann T: The diacylgylcerol-sensitive TRPC3/6/7 subfamily of cation channels: functional characterization and physiological relevance. Pflugers Arch 2005, 451:72-80.

19. Helliwell RM, Large WA: Alpha 1-adrenoceptor activation of a nonselective cation current in rabbit portal vein by 1,2-diacyl-sn-glycerol. $J$ Physiol 1997, 499(Pt 2):417-428.

20. Inoue $R$, Okada $T$, Onoue $H$, Hara $Y$, Shimizu S, Naitoh $S$, Ito $Y$, Mori $Y$ : The transient receptor potential protein homologue TRP6 is the essential component of vascular alpha(1)-adrenoceptor-activated $\mathrm{Ca}(2$ +)-permeable cation channel. Circ Res 2001, 88:325-332.

21. Freichel M, Vennekens R, Olausson J, Hoffmann M, Muller C, Stolz S, Scheunemann J, Weissgerber P, Flockerzi V: Functional role of TRPC proteins in vivo: lessons from TRPC-deficient mouse models. Biochem Biophys Res Commun 2004, 322:1352-1358.

22. Merida I, vila-Flores A, Merino E: Diacylglycerol kinases: at the hub of cell signalling. Biochem J 2008, 409:1-18.

23. Weissmann N, Akkayagil E, Quanz K, Schermuly RT, Ghofrani HA, Fink L, Hanze J, Rose F, Seeger W, Grimminger F: Basic features of hypoxic pulmonary vasoconstriction in mice. Respir Physiol Neurobiol 2004, 139:191-202.

24. Weissmann N, Grimminger F, Walmrath D, Seeger W: Hypoxic vasoconstriction in buffer-perfused rabbit lungs. Respir Physiol 1995, 100:159-169.

25. Bolla M, You D, Loufrani L, Levy BI, Levy-Toledano S, Habib A, Henrion D: Cyclooxygenase involvement in thromboxane-dependent contraction in rat mesenteric resistance arteries. Hypertension 2004, 43:1264-1269.

26. Bennie RE, Packer CS, Powell DR, Jin N, Rhoades RA: Biphasic contractile response of pulmonary artery to hypoxia. Am J Physiol 1991, 261:L156-L163.

27. Rebecchi MJ, Pentyala SN: Structure, function, and control of phosphoinositide-specific phospholipase C. Physiol Rev 2000, 80:1291-1335. 
28. Domino KB, Chen L, Alexander CM, Williams JJ, Marshall C, Marshall BE: Time course and responses of sustained hypoxic pulmonary vasoconstriction in the dog. Anesthesiology 1984, 60:562-566.

29. Welling KL, Sanchez R, Ravn JB, Larsen B, Amtorp O: Effect of prolonged alveolar hypoxia on pulmonary arterial pressure and segmental vascular resistance. J Appl Physiol 1993, 75:1194-1200.

30. Woodmansey PA, Zhang F, Channer KS, Morice AH: Effect of the calcium antagonist amlodipine on the two phases of hypoxic pulmonary vasoconstriction in rat large and small isolated pulmonary arteries. $J$ Cardiovasc Pharmacol 1995, 25:324-329.

31. Ozaki M, Marshall C, Amaki Y, Marshall BE: Role of wall tension in hypoxic responses of isolated rat pulmonary arteries. Am J Physiol 1998, 275 L1069-L1077.

32. Hofmann T, Obukhov AG, Schaefer M, Harteneck C, Gudermann T, Schultz G: Direct activation of human TRPC6 and TRPC3 channels by diacylglycerol. Nature 1999, 397:259-263.

33. Trebak M, Vazquez G, Bird GS, Putney JW Jr: The TRPC3/6/7 subfamily of cation channels. Cell Calcium 2003, 33:451-461.

34. Friedlander G, Le GC, Sraer J, Amiel C: 12-HETE modulates Na-coupled uptakes in proximal tubular cells: role of diacylglycerol kinase inhibition. Am J Physiol 1990, 259:F816-F822.

35. Patterson RL, van Rossum DB, Nikolaidis N, Gill DL, Snyder SH: Phospholipase C-gamma: diverse roles in receptor-mediated calcium signaling. Trends Biochem Sci 2005, 30:688-697.

36. Wynne BM, Chiao CW, Webb RC: Vascular Smooth Muscle Cell Signaling Mechanisms for Contraction to Angiotensin II and Endothelin-1. J Am Soc Hypertens 2009, 3:84-95.

37. Thompson AK, Mostafapour SP, Denlinger LC, Bleasdale JE, Fisher SK: The aminosteroid U-73122 inhibits muscarinic receptor sequestration and phosphoinositide hydrolysis in SK-N-SH neuroblastoma cells. A role for Gp in receptor compartmentation. J Biol Chem 1991, 266:23856-23862.

38. Alapati VR, McKenzie C, Blair A, Kenny D, MacDonald A, Shaw AM: Mechanisms of U46619- and 5-HT-induced contraction of bovine pulmonary arteries: role of chloride ions. Br J Pharmacol 2007, 151:1224-1234.

39. Archer SL, Reeve HL, Michelakis E, Puttagunta L, Waite R, Nelson DP, Dinauer MC, Weir EK: O2 sensing is preserved in mice lacking the gp91 phox subunit of NADPH oxidase. Proc Natl Acad Sci USA 1999, 96:7944-7949.

40. Sutendra G, Bonnet S, Rochefort G, Haromy A, Folmes KD, Lopaschuk GD, Dyck JR, Michelakis ED: Fatty acid oxidation and malonyl-CoA decarboxylase in the vascular remodeling of pulmonary hypertension. Sci Transl Med 2010, 2:44ra58.

41. Fuchs B, Sommer N, Dietrich A, Schermuly RT, Ghofrani HA, Grimminger F, Seeger W, Gudermann T, Weissmann N: Redox signaling and reactive oxygen species in hypoxic pulmonary vasoconstriction. Respir Physiol Neurobiol 2010, 174:282-291.

42. Sommer N, Dietrich A, Schermuly RT, Ghofrani HA, Gudermann T, Schulz R, Seeger W, Grimminger F, Weissmann N: Regulation of hypoxic pulmonary vasoconstriction: basic mechanisms. Eur Respir J 2008, 32:1639-1651.

43. Waypa GB, Schumacker PT: Hypoxic pulmonary vasoconstriction: redox events in oxygen sensing. J Appl Physiol 2005, 98:404-414.

44. Archer SL, London B, Hampl V, Wu X, Nsair A, Puttagunta L, Hashimoto K, Waite RE, Michelakis ED: Impairment of hypoxic pulmonary vasoconstriction in mice lacking the voltage-gated potassium channel Kv1.5. FASEB J 2001, 15:1801-1803.

45. Archer SL, Souil E, nh-Xuan AT, Schremmer B, Mercier JC, El YA, NguyenHuu L, Reeve HL, Hampl V: Molecular identification of the role of voltagegated K+ channels, Kv1.5 and Kv2.1, in hypoxic pulmonary vasoconstriction and control of resting membrane potential in rat pulmonary artery myocytes. J Clin Invest 1998, 101:2319-2330.

46. Dietrich A, Kalwa H, Fuchs B, Grimminger F, Weissmann N, Gudermann T: In vivo TRPC functions in the cardiopulmonary vasculature. Cell Calcium 2007, 42:233-244.

47. Cornfield DN, Stevens T, McMurtry IF, Abman SH, Rodman DM: Acute hypoxia increases cytosolic calcium in fetal pulmonary artery smooth muscle cells. Am J Physiol 1993, 265:L53-L56.

48. Salvaterra CG, Goldman WF: Acute hypoxia increases cytosolic calcium in cultured pulmonary arterial myocytes. Am J Physiol 1993, 264:L323-L328.
49. Vadula MS, Kleinman JG, Madden JA: Effect of hypoxia and norepinephrine on cytoplasmic free $\mathrm{Ca} 2+$ in pulmonary and cerebral arterial myocytes. Am J Physiol 1993, 265:L591-L597.

50. Zhang F, Carson RC, Zhang H, Gibson G, Thomas HM III: Pulmonary artery smooth muscle cell $[\mathrm{Ca} 2+] \mathrm{i}$ and contraction: responses to diphenyleneiodonium and hypoxia. Am J Physiol 1997, 273:L603-L611.

51. Ward JP, Robertson TP: The role of the endothelium in hypoxic pulmonary vasoconstriction. Exp Physiol 1995, 80:793-801.

52. Waypa GB, Chandel NS, Schumacker PT: Model for hypoxic pulmonary vasoconstriction involving mitochondrial oxygen sensing. Circ Res 2001, 88:1259-1266.

53. Sham JS, Crenshaw BR, Deng LH, Shimoda LA, Sylvester JT: Effects of hypoxia in porcine pulmonary arterial myocytes: roles of $K(V)$ channel and endothelin-1. Am J Physiol Lung Cell Mol Physiol 2000, 279:L262-L272.

54. Leach RM, Hill HM, Snetkov VA, Robertson TP, Ward JP: Divergent roles of glycolysis and the mitochondrial electron transport chain in hypoxic pulmonary vasoconstriction of the rat: identity of the hypoxic sensor. $J$ Physiol 2001, 536:211-224.

doi:10.1186/1465-9921-12-20

Cite this article as: Fuchs et al:: Diacylglycerol regulates acute hypoxic pulmonary vasoconstriction via TRPC6. Respiratory Research 2011 12:20.

\section{Submit your next manuscript to BioMed Central and take full advantage of:}

- Convenient online submission

- Thorough peer review

- No space constraints or color figure charges

- Immediate publication on acceptance

- Inclusion in PubMed, CAS, Scopus and Google Scholar

- Research which is freely available for redistribution

Submit your manuscript at www.biomedcentral.com/submit
C) Biomed Central 